\title{
A transient enhanced DVS DC-DC converter based on state trajectory analysis
}

\author{
Jun Liu • Leicheng Chen • Shiquan Fan • \\ Li Geng
}

Received: 2 May 2012/Revised: 25 February 2014 / Accepted: 28 February 2014/Published online: 15 March 2014

(C) The Author(s) 2014. This article is published with open access at Springerlink.com

\begin{abstract}
Dynamic voltage scaling (DVS) can effectively reduce energy consumption by dynamically varying the supply voltage of the system accordingly to the clock frequency. A new DVS-enabled DC-DC converter is presented in this paper. State trajectory is employed to analyze the transient features of PWM and PFM Buck converters. A novel transient enhancement circuit is designed to improve the transient response of the DVS-enabled Buck converter. To further expand the output voltage range of the converter, a current-starved voltage controlled delay line is proposed in the controller of DC-DC converter to obtain an ultra low voltage of $0.5 \mathrm{~V}$. When the input voltage is $3.3 \mathrm{~V}$, the output voltage of the converter can be dynamically regulated from 0.5 to $2.0 \mathrm{~V}$. The output voltage tracking speed is less than $7.5 \mu \mathrm{s} / \mathrm{V}$ and the recovery speed is $33 \mu \mathrm{s} / \mathrm{A}$ for a load current step from 0.6 to $0.2 \mathrm{~A}$ at output voltage of $0.5 \mathrm{~V}$. The chip area is $1.75 \mathrm{~mm} \times 1.33 \mathrm{~mm}$ in a $0.18 \mu \mathrm{m}$ standard CMOS process.
\end{abstract}

Keywords Dynamic voltage scaling - DC-DC converter . Fast response - Transient enhancement - Low voltage

\section{Introduction}

DC-DC converter has been regarded as the core of the power management unit. Nowadays, dynamic voltage scaling (DVS) is widely used to reduce power consumption by adjusting the supply voltage of the system. Thus it urgently needs to develop the DC-DC converter whose output

J. Liu $\cdot$ L. Chen $\cdot$ S. Fan $\cdot$ L. Geng $(\bowtie)$

School of Electronics and Information Engineering, Xi'an Jiaotong University, Xianning Road 28, Xi' an 710049, China

e-mail: gengli@mail.xjtu.edu.cn voltage can be dynamically regulated with fast response speed. Apart from the high power conversion efficiency, two other considerations should be taken into account in DVS enabled converter. One is the demanding requirement in transient response [1-3], and the other is the range of the output voltage. Power supply voltage becomes lower and lower in system-on-chip (SoC) integration due to the technology shrinking tendency. Thus DC-DC converters with high dynamic response and low minimum output voltage have attracted more and more attentions.

Many techniques have been proposed to improve the transient behaviors of the switching DC-DC converters. To speed up the transient response, a dual-mode control is proposed in [4], which enables hysteretic control during transient and resumes normal voltage-mode control at steady state. In [5, 6], a fast transient recovery circuit is proposed to achieve a high slew rate of load variation in a voltage-mode Buck converter. In [7, 8], a pulse-train control scheme and a PWM controller are reported. Two states can be transited seamlessly depending on the dynamic operating status. All above techniques are aimed at the non-DVS system and they distinguishes the operating mode of the converter by a fixed threshold band. However, in the DVS utilization, different thresholds are required because the output voltage of the converter is dynamically changed. It brings some difficulties on the loop analysis and transient design.

Moreover, for a DVS enabled system, transient behaviors become more important especially on the output voltage tracking features. Actually, state trajectory is a good method to help us know more behavior details about the switching DC-DC converters. In [9], state trajectory is used to analyze the transient response of the switching converter and a free-running control law is developed. Based on the state trajectory predictions, an enhanced free- 
running control law is proposed in a hysteretic Buck converter to improve the transient behaviors [10]. As a result, the output voltage can reach its steady state within two switching periods even under a large transient step. State trajectory is used to study the large signal stability of the switching converter in [11].

In this paper, a DVS-enabled Buck converter with low output voltage and fast transient response is presented. State trajectory is used to analyze the transient behaviors of PWM and PFM Buck converters, respectively. A transient enhancement circuit is proposed to improve the transient and overshooting of the converter. Additionally, a currentstarved voltage controlled delay line (VCDL) is designed in the controller to reduce the minimal output voltage of the converter. The proposed DVS-enabled Buck converter is designed in a $0.18 \mu \mathrm{m}$ CMOS technology. It can dynamically regulate the voltage from 0.5 to $2.0 \mathrm{~V}$ with an input voltage of $3.3 \mathrm{~V}$. The output-voltage and load tracking capability are both improved greatly.

The transient features of different converters are discussed by using state trajectory in Sect. 2 . The structure and the detailed circuit implementation of the proposed DC-DC converter are described in Sect. 3. The design results and the chip layout are provided in Sect. 4. Finally, conclusion is given in Sect. 5.

\section{Transient analysis of the converters by state trajectory method}

There exist different mathematical methods to analyze the switching DC-DC converters. State trajectory is regarded as one of the good methods to examine the transient behaviors [9]. In this section, state trajectory is employed to analyze the transient response of a voltage-mode PWM Buck converter and a hysteretic PFM Buck converter, respectively.

\subsection{State trajectories of the Buck converter}

The schematic diagram of a Buck converter is shown in Fig. 1. Its behavior can be represented mathematically by a sequence of differential equations. Then the time-domain state solutions can be obtained. For different time intervals, the corresponding state equations are as follows:

When $M_{1}$ is on and $M_{2}$ is off, the time-domain differential equations are

$$
\left\{\begin{array}{l}
L \frac{d i_{L}}{d t}=V_{\text {in }}-\left(v_{C}+C \frac{d v_{C}}{d t} \times R_{C}\right)-R_{L} \times i_{L} \\
C \frac{d v_{C}}{d t}=i_{L}-\frac{1}{R_{\text {load }}} \times\left(v_{C}+C \frac{d v_{C}}{d t} \times R_{C}\right)
\end{array}\right.
$$

The inductor current $i_{\mathrm{L}}$ and the capacitor voltage $v_{\mathrm{C}}$ are state variables. $V_{\text {in }}$ is the input voltage of the Buck converter,

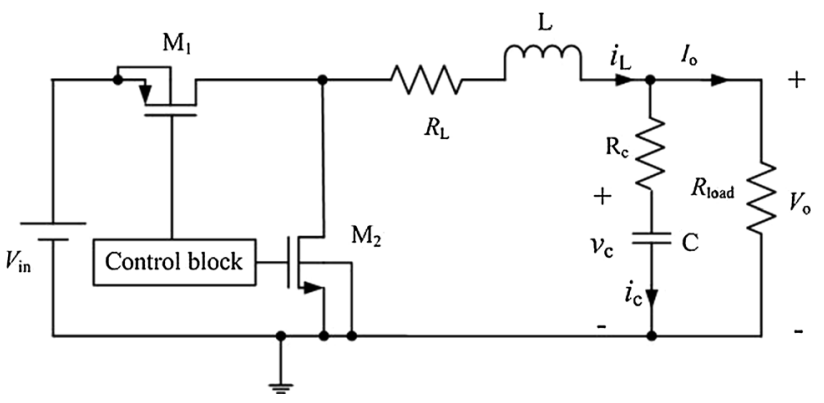

Fig. 1 Schematic diagram of the Buck converter

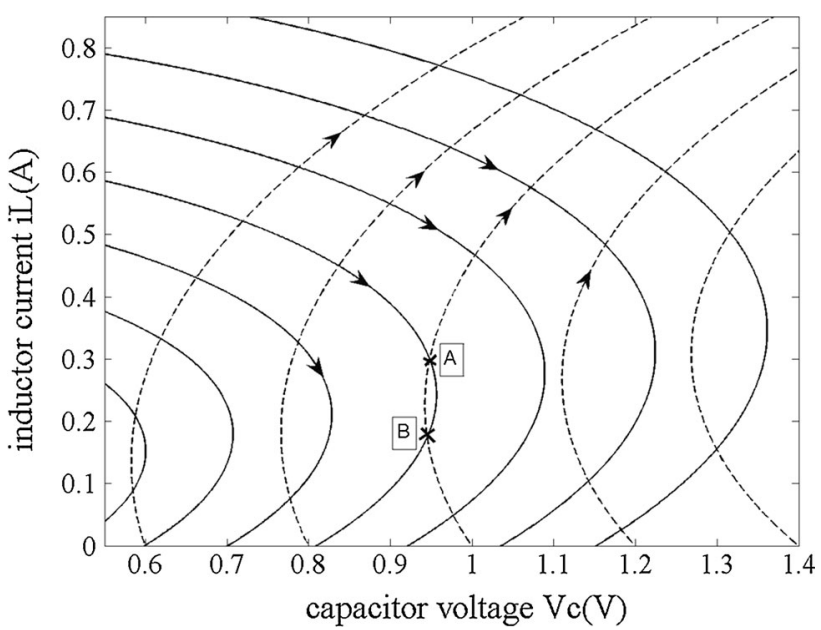

Fig. 2 Families of $\mathrm{M}_{1}$-on trajectories (directional dash lines) and $\mathrm{M}_{1}$-off trajectories (directional solid lines) in the state plane of $i_{\mathrm{L}}$ versus $v_{\mathrm{C}}$ with $V_{\text {in }}=3.3 \mathrm{~V}, L=5 \mu \mathrm{H}, C=1 \mu \mathrm{F}$ and $R_{\text {load }}=4 \Omega$. Directional closed curve $A B A$ represents one of the steady-state trajectories

$R_{\text {load }}$ is the load resistance. $R_{\mathrm{C}}$ and $R_{\mathrm{L}}$ are the parasitic resistance of the capacitor and the inductor, respectively. $v_{\mathrm{C}}\left(t_{0}\right)$ and $i_{\mathrm{L}}\left(t_{0}\right)$ represent the arbitrary initial state variables of the converter, and $t_{0}$ is an arbitrary initial time.

Similarly, when $\mathrm{M}_{1}$ turns off and $\mathrm{M}_{2}$ turns on, the differential equations are

$$
\left\{\begin{array}{l}
L \frac{d i_{L}}{d t}=-\left(v_{C}+C \frac{d v_{C}}{d t} \times R_{C}\right)-R_{L} \times i_{L} \\
C \frac{d v_{C}}{d t}=i_{L}-\frac{1}{R_{\text {load }}} \times\left(v_{C}+C \frac{d v_{C}}{d t} \times R_{C}\right)
\end{array}\right.
$$

These differential equations, when plotted in a state plane of $i_{\mathrm{L}}$ versus $v_{\mathrm{C}}$, are defined as the state trajectories. In Fig. 2, the directional dash lines are called $\mathrm{M}_{1}$-on trajectories which decided by Eq. (1). The directional solid lines are $\mathrm{M}_{1}$-off trajectories which decided by Eq. (2). The operations of the converter can be observed as series trajectory connections of $\mathrm{M}_{1}$-on and $\mathrm{M}_{1}$-off. The closed curve, which consisting of one $\mathrm{M}_{1}$-on trajectory and one $\mathrm{M}_{1}$-off trajectory, is one steady-state of the converter. 

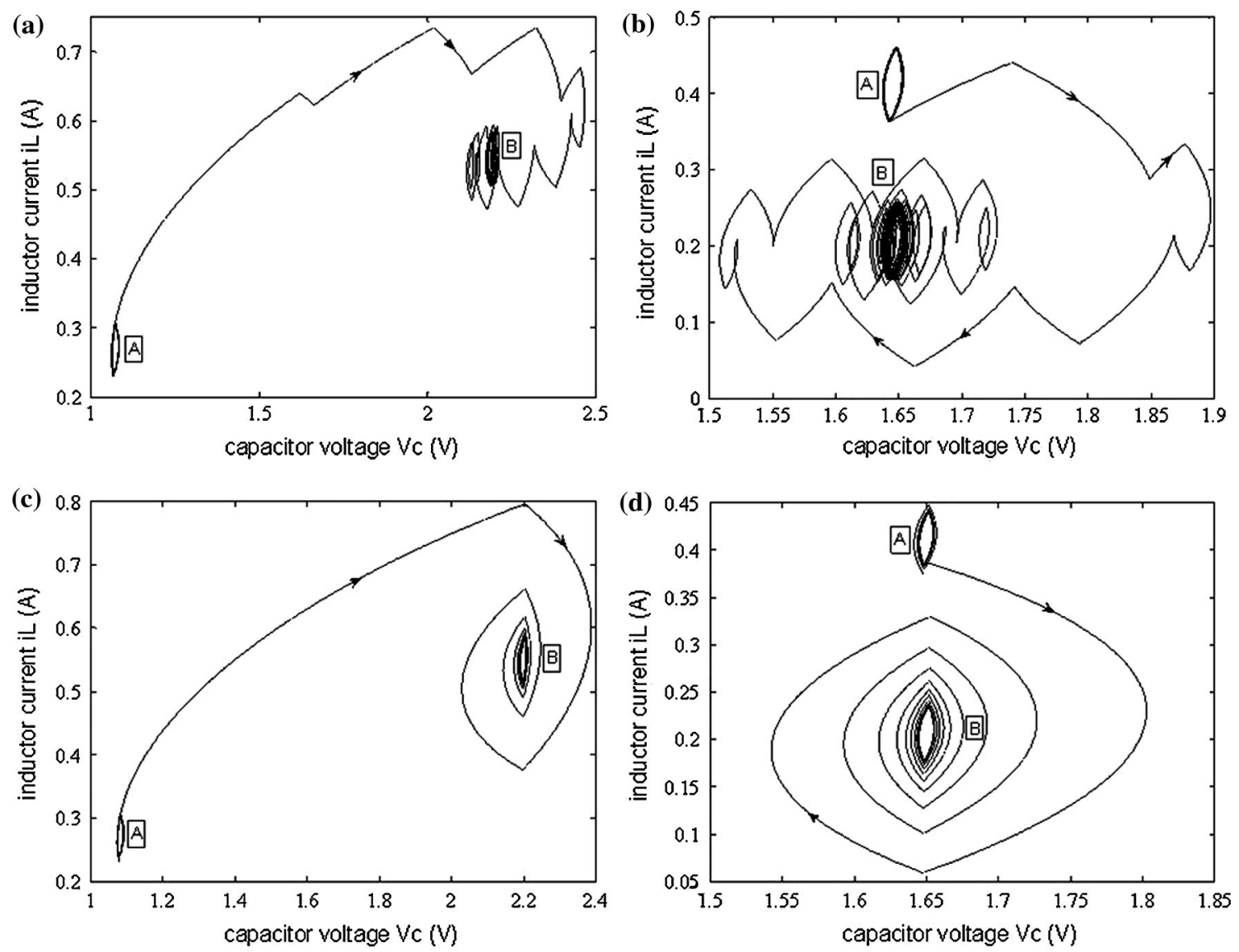

Fig. 3 State trajectories of Buck converters: a PWM converter with output-voltage step change, b PWM converter with load-current step change, $\mathbf{c}$ PFM converter with output-voltage step change and d PFM converter with load-current step change

\subsection{Transient response comparison based on state trajectory}

To show the transient behaviors, a voltage-mode PWM Buck converter and a hysteretic PFM Buck converter are built, where $V_{\text {in }}$ is $3.3 \mathrm{~V}$, the filter capacitor $C$ is $1 \mu \mathrm{F}$, the inductor $L$ is $10 \mu \mathrm{H}$, the output load $R_{\text {load }}$ is $4 \Omega$ and the parasitic resistance of inductor and capacitor are all $50 \mathrm{~m} \Omega$. The switching frequency $f_{\mathrm{s}}$ is $800 \mathrm{kHz}$. When the above parameters are substituted in Eqs. (1) and (2), the state trajectories corresponding to an output-voltage step changed from 1.08 to $2.2 \mathrm{~V}$ and a load-current step changed from 412.5 to $206.25 \mathrm{~mA}$ for the voltage-mode PWM Buck converter are shown in Fig. 3(a, b), respectively, where " $A$ " represents the initial state and " $B$ " is the final state. The state of the converter alternately follows $\mathrm{M}_{1}$-on and $\mathrm{M}_{1}$-off trajectories in the state plane, and eventually, converges to a closed steady-state trajectory curve. Two adjacent segments of state trajectories represent an on/off switching cycle. The state trajectories of the hysteretic PFM Buck converter with an output-voltage step change from 1.08 to $2.2 \mathrm{~V}$ and a load-current step change from
412.5 to $206.25 \mathrm{~mA}$ are also shown in Fig. 3(c, d), respectively.

Comparing the transient response behaviors in Fig. 3, we can see that the hysteretic PFM converter exhibits faster transient features than the voltage-mode PWM converter either in the output-voltage step change or the load-current step change because fewer switching cycles are needed to reach the final steady state. For the DVS applications, in order to speed up the transient behaviors the hysteretic control is selected in this work.

\section{System design and circuit implementation of the proposed converter}

\subsection{DVS operation and system topology}

A DVS system block diagram is shown in Fig. 4 [12]. It consists of a DVS-enabled DC-DC converter, a microprocessor and a DVS algorithm block. The DVS-enabled DC-DC converter provides the dynamically regulated voltage $V_{\mathrm{DD}}$ to the microprocessor. The software algorithm 


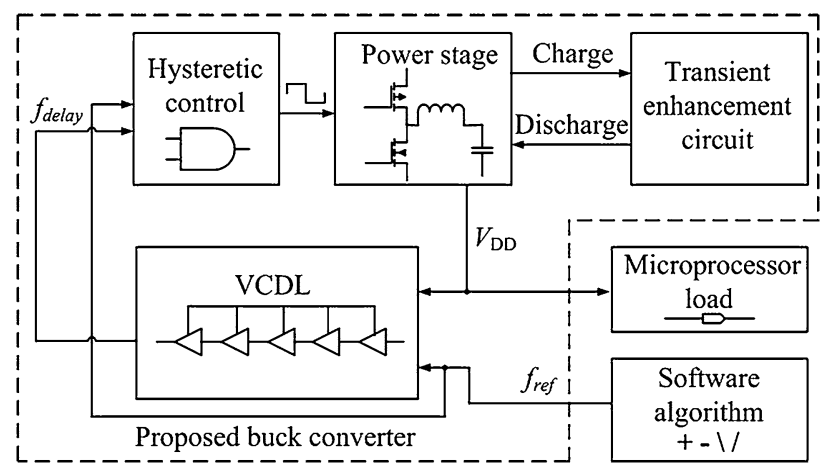

Fig. 4 Block diagram of a DVS system with hysteretic Buck converter

is employed in the microprocessor to calculate the optimal supply voltage for maintaining the minimum power dissipation of the microprocessor. The power stage block, hysteretic controller and VCDL constitute a basic DVSenabled DC-DC converter. Frequency signal $f_{\text {ref }}$ is sent to the VCDL. By detecting the phase difference between $f_{\text {ref }}$ and the output signal $f_{\text {delay }}$ of the VCDL, the hysteretic controller generates different duty ratio signals to control the on/off of the power transistors providing the required optimal supply to the microprocessor. In addition, sometimes, in order to improve the voltage tracking capability, the transient enhancement circuit is added for DVS system. Note that the output voltage of converter $V_{\mathrm{DD}}$ is also the control voltage $V_{\text {ctrl }}$ of VCDL, which determines the time delay of the VCDL.

\subsection{Design of the transient enhancement circuit}

For DVS application, switching DC-DC converters should have fast voltage tracking speed. Many techniques have been proposed to improve the transient behaviors. In [13], a fast transient double Buck converter is proposed. Two control mode are used to achieve linear and nonlinear control strategies during the steady and transient period, respectively. It speeds up the transient speed greatly. In this paper, we give the state trajectory analysis of the double Buck converter and then proposed a novel transient enhanced double Buck converter.

\subsubsection{Transient response of the previous double Buck technique}

Figure 5 shows a voltage-mode double Buck converter architecture [13]. A main converter and an auxiliary converter are connected in parallel. They play different roles in the converter. The main converter focuses on the loop stability and the low output voltage ripple, while the auxiliary converter provides or takes out current from the output when the output voltage exceeds the voltage thresholds.

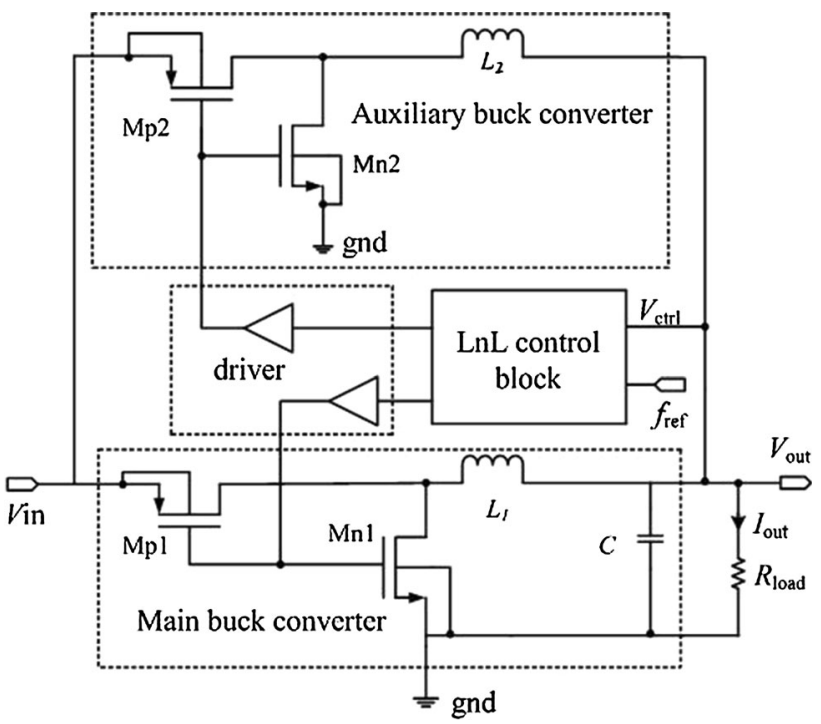

Fig. 5 Block diagram of the double Buck converter

We can also apply the hysteretic control in the double Buck converter. The corresponding parameters are: $V_{\text {in }}=3.3 \mathrm{~V}$, the inductance of main inductor $L_{1}$ is $10 \mu \mathrm{H}$, the auxiliary inductance $L_{2}=2 \mu \mathrm{H}$, the filter capacitance $C=1 \mu \mathrm{F}$ and $R_{\text {load }}$ is $4 \Omega$. The parasitic resistance of $L_{1}$, $L_{2}$ and $C$ are all $50 \mathrm{~m} \Omega$. The threshold band of hysteretic control is defined as $0.1 \mathrm{~V}$. The state trajectories are therefore obtained, shown in Fig. 6.

Figure 6(a) illustrates the state trajectories for an outputvoltage step from 1.08 to $2.2 \mathrm{~V}$. After several switching periods, the converter state moves from the initial steady state "A" into the threshold band and gradually arrives at the final steady state "B". For double Buck, if the output voltage is within the threshold band, only the main switching converter operates. It likes a typical Buck converter. If the output voltage goes out of the threshold band, the auxiliary converter works. In Fig. 6(a), when the state trajectory enters the threshold band, the auxiliary converter should stop operating. However, because a large quantity of current have stored in $\mathrm{L}_{2}$ during the up-step transient, the current continues to charge the filter capacitor through the parasitic diode $\mathrm{D}_{1}$ of $\mathrm{Mn} 2$. It forces the state trajectory run out of the threshold band again. In order to make the output voltage go back into the threshold band, Mn2 should be turned on to discharge the filter capacitor $\mathrm{C}$. But the discharging behavior could not take effect until the current stored in $\mathrm{L}_{2}$ exhausts and begins to reverse. As a result, an unexpected inductor current oscillation occurs, which resulting the state trajectory path of NOPQ, slows down the voltage tracking speed of the converter.

During the transient period of a load-current change of 412.5-206.25 mA, as shown in Fig. 6(b), the current stored in $L_{2}$ is not large enough to generate the oscillation 

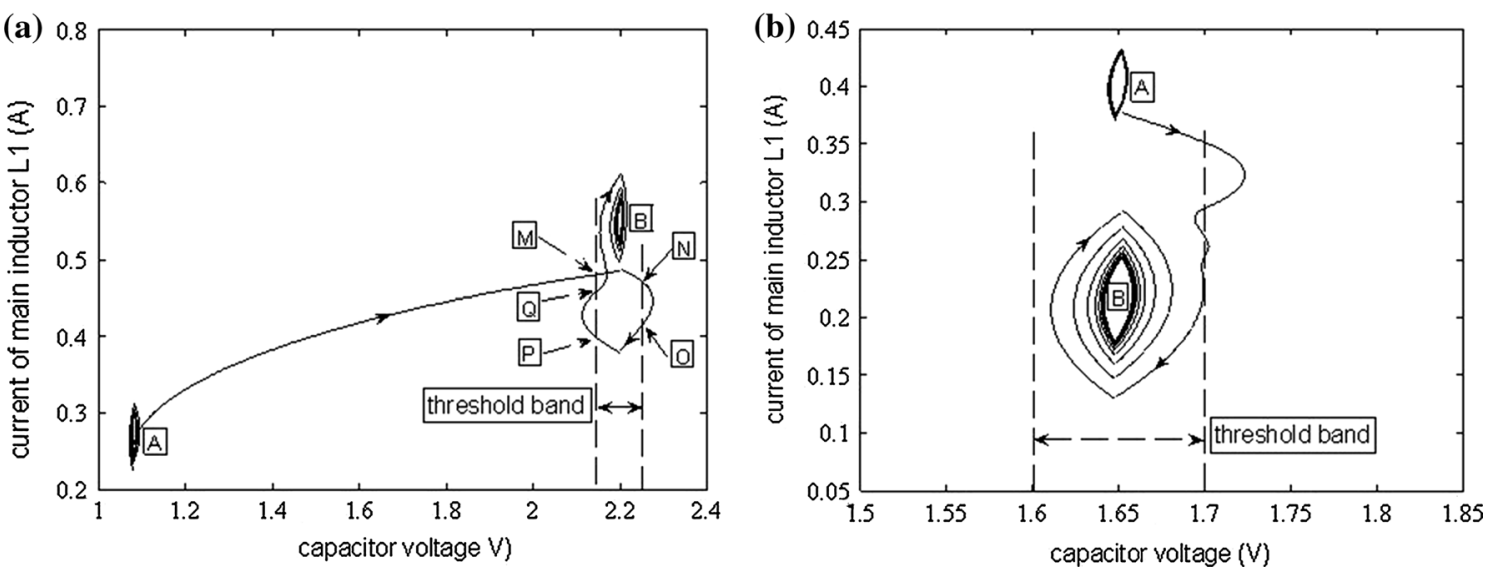

Fig. 6 State trajectories of the double Buck converter during transient periods: a output-voltage step change and b load-current step change

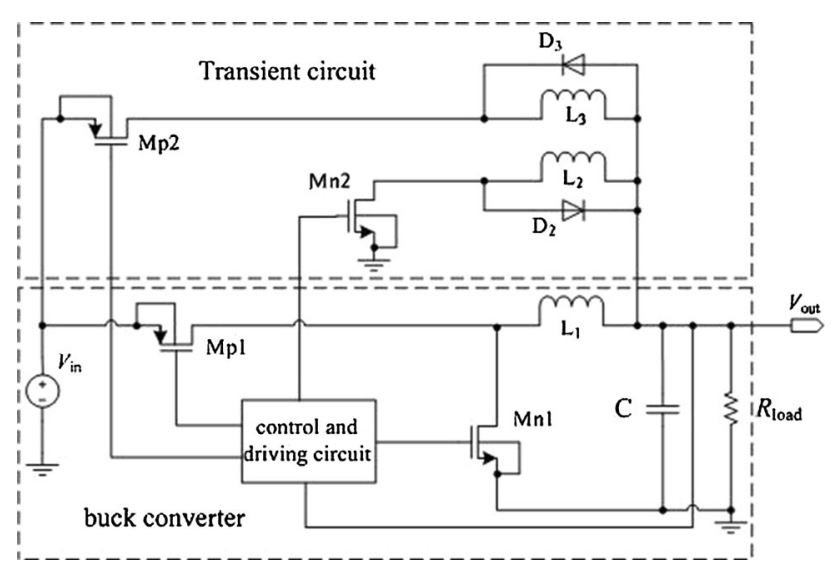

Fig. 7 New transient enhanced double Buck converter

explained above. Thus a relatively faster recovering time and lower overshooting voltage are obtained.

Compared to the state trajectories of the single Buck converter shown in Fig. 3(c, d), the double Buck converter has less voltage overshooting and exhibits better transient behaviors.

\subsubsection{New transient enhanced double Buck converter}

Previous double Buck converter suffers from the inductor current oscillation. Moreover, when there is a large outputvoltage variation, such as the converter start-up period, it suffers from large voltage overshooting. To solve this problem, a novel transient enhancement circuit is proposed in this work.

The structure of transient enhancement circuit is shown in Fig. 7. It is composed of a main power converter loop and two auxiliary current paths. $\mathrm{Mn} 2$ and $\mathrm{L}_{2}$ constitute one auxiliary path while $\mathrm{Mp} 2$ and $\mathrm{L}_{3}$ constitute the other one. $\mathrm{D}_{2}$ and $\mathrm{D}_{3}$ are two current bypasses. Two current bypasses
Table 1 Operation mode of the proposed converter

\begin{tabular}{|c|c|c|c|}
\hline Voltage range & Operation mode & $\begin{array}{l}\text { On/off state } \\
\text { of } \mathrm{Mp} 1 / \mathrm{Mn} 1\end{array}$ & $\begin{array}{l}\text { On/off state } \\
\text { of } \mathrm{Mp} 2 / \mathrm{Mn} 2\end{array}$ \\
\hline$\left[0, V_{o}-\Delta V_{o}\right]$ & $\begin{array}{l}\text { Low-voltage } \\
\text { transient mode }\end{array}$ & On/off & On/off \\
\hline$\left[V_{o}-\Delta V_{o}, V_{o}\right]$ & Steady-state mode & On/off & Off/off \\
\hline$\left[V_{o}, V_{o}+\Delta V_{o}\right]$ & Steady-state mode & Off/on & Off/off \\
\hline$\left[V_{o}+\Delta V_{o}, V_{d d}\right]$ & $\begin{array}{l}\text { High-voltage } \\
\text { transient mode }\end{array}$ & Off/on & Off/on \\
\hline
\end{tabular}

degrade the inductor's current in terms of the RL loop. Because they are totally independent of the main converter loop, it will not induce the non-stability issues.

Table 1 lists the operation mode of the proposed converter, where $V_{\mathrm{o}}$ is the output voltage and $2 \Delta V_{\mathrm{o}}$ represents the threshold band. For the DVS application, $V_{\mathrm{o}}$ is dynamically changed. If the output voltage is within the threshold range, only the main converter loop works. Difference appears when the state trajectory moves into the threshold band. For the pervious double Buck converter, the auxiliary converter is forced to shut down, the current stored in $\mathrm{L}_{2}$ is charged or discharged through the parasitic diodes of Mp2 or Mn2. Since the charge and discharge actions have to be completed through one current path and the direction of the auxiliary inductor current could not be changed instantaneously, it needs longer transient recovery time. However, for the proposed structure, although the power switches are disabled during the transient period, the current bypass diode $\mathrm{D}_{2}$ and $\mathrm{D}_{3}$ provide the auxiliary current path to avoid the same charge and discharge path described above.

The state trajectories are drawn to illustrate the transient response of the converter. $\mathrm{L}_{2}$ and $\mathrm{L}_{3}$ are both $2 \mu \mathrm{H}$ and the threshold band $2 \Delta V_{\mathrm{o}}$ is $0.1 \mathrm{~V}$. The state trajectories of the 

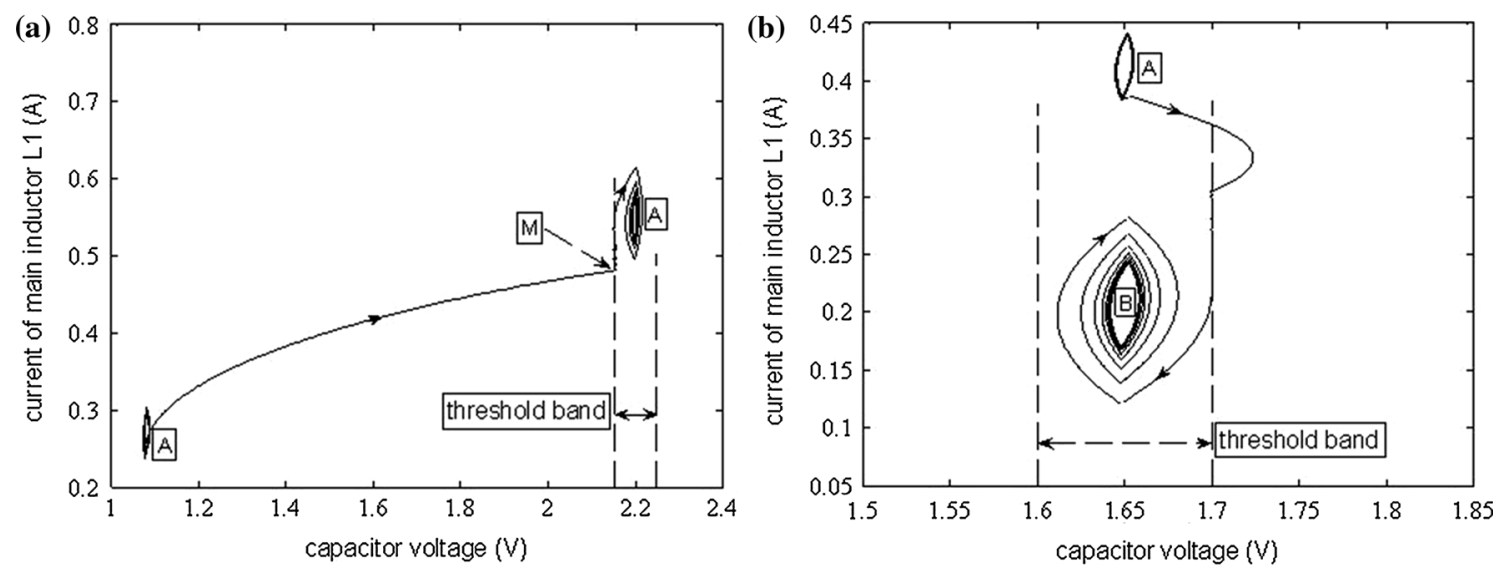

Fig. 8 State trajectories of the proposed converter in transient periods: a output-voltage step change and b load-current step change

converter with an output-voltage step change and a loadcurrent step change are presented in Fig. 8. As shown in Fig. 8(a), after passing point "M", the state trajectory staggers along the low threshold boundary and moves into the threshold band. Consequently, oscillation appears in Fig. 6(a) is avoided. The load transient behavior in Fig. 8(b) is similar with that of Fig. 6(b). The proposed transient enhancement circuit maintains excellent currentstep transient characteristic and exhibits superior voltagestep transient characteristics, which shows more attractive for the DVS applications.

\subsection{Current-starved VCDL for lowering the minimum output voltage of the converter}

\subsubsection{Operational principle of VCDL based Buck converter}

VCDL is used to construct a hysteretic controller, as shown in Fig. 9(a). It consists of quantities of delay cells. When a frequency signal of $f_{\text {ref }}$ is applied to the input of VCDL, it passes through delay cells and being sampled by $f_{\text {ref }}$ again at the output. The propagation delay $t_{\text {delay }}$ is determined by the control voltage $V_{\text {ctrl }}$, which is equals to the output voltage of converter. When $V_{\text {ctrl }}$ decreases, $t_{\text {delay }}$ increases. The falling edge of the delay signal passes the sampling edge, as shown in Fig. 9(b). The output of D flip-flop becomes " 1 " and power transistor Mp turns on. The inductor is charged and the output voltage increases. On the contrary, if $V_{\text {ctrl }}$ increases, $t_{\text {delay }}$ decreases. The falling edge of delay signal does not reach the sampling edge, as shown in Fig. 9(c). The output of D flip-flop keeps its initial value of " 0 ". In this case, the inductor is discharged and the output voltage of the converter is reduced. On the other hand, if $f_{\text {ref }}$ decreases, the falling edge of the delay signal will not reach the sampling edge, as shown in
Fig. 9(d). The output of D flip-flop becomes "0", and the inductor discharges current from output capacitor, resulting decrease of the output voltage. Similarly, for a increased $f_{\text {ref }}$, as shown in Fig. 9(e), the output voltage is increased.

When the VCDL based Buck converter is operating in its steady state, the propagation delay $t_{\text {delay }}$ and $f_{\text {ref }}$ satisfy the following relationship:

$t_{\text {delay }}=\frac{1}{2 f_{\text {ref }}}$

For the DVS-enabled converter, an excellent linearity between the output voltage and the reference frequency $f_{\text {ref }}$ is required. An inverse proportion between the control voltage $V_{\text {ctrl }}$ and the delay time $t_{\text {delay }}$ is required to compensate the nonlinearity between $t_{\text {delay }}$ and $f_{\text {ref }}$ according to Eq. (3).

\subsubsection{Current-starved VCDL}

In order to regulate the output voltage as low as $0.5 \mathrm{~V}$, VCDL should effectively operate in sub-threshold region. Traditional CMOS-inverter based VCDL shows approximate inverse-proportion feature between $V_{\text {ctrl }}$ and $t_{\text {delay }}$ when $V_{\text {ctrl }}$ is much higher than the threshold voltage of the MOSFETs. But when $V_{\text {ctrl }}$ is lower or approximate to the threshold voltage, CMOS-inverter based VCDL lost the good inverse-proportion feature between $V_{\text {ctrl }}$ and $t_{\text {delay. In }}$ this work, a current-starved VCDL is proposed to improve the non-linearity at low voltage under the threshold voltage of the MOSFETs. The current-starved VCDL is shown in Fig. 10, which consists of quantities of current-starved inverters and a $\mathrm{V}-\mathrm{I}$ converter. By controlling the charge or discharge current of the output parasitic capacitor of each current-starved inverter, the propagation delay of the delay line can be regulated. Time delay of one current-starved inverter is as follows [14]: 

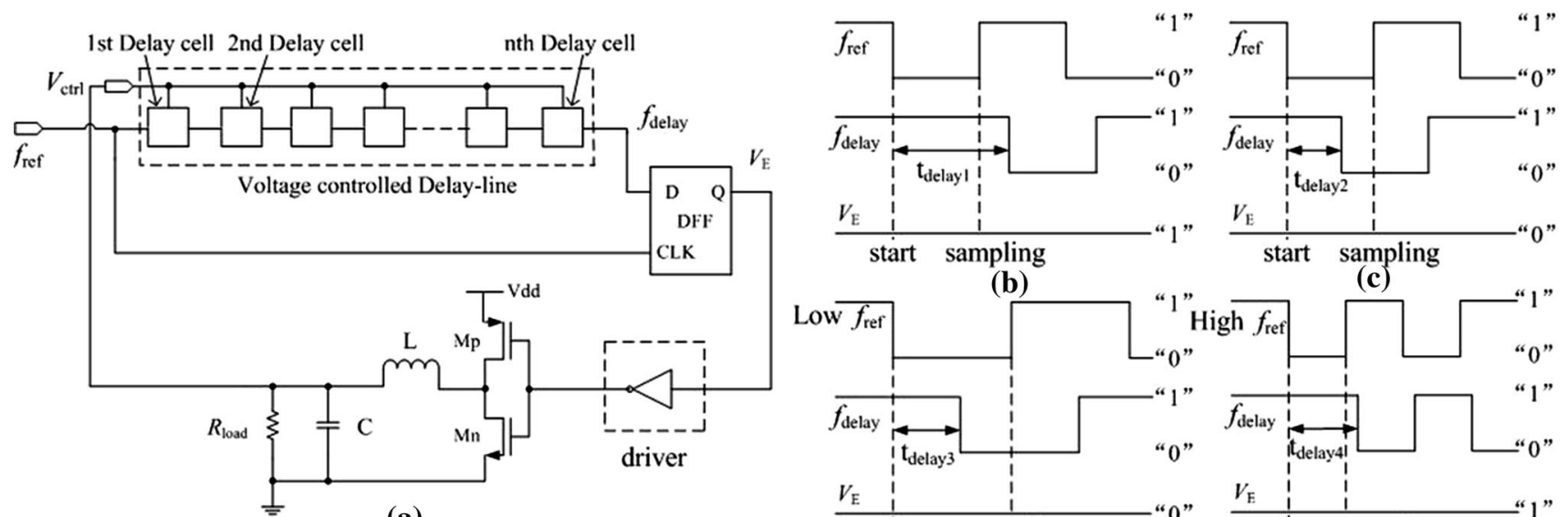

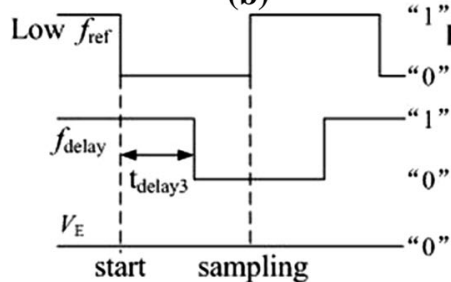

(d)

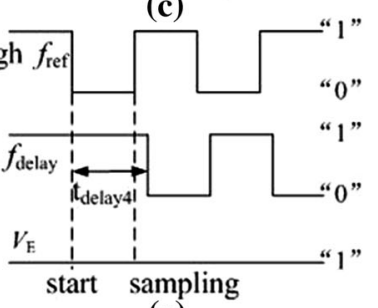

(e)

Fig. 9 Operational principle of VCDL based Buck converter: a block diagram of the VCDL based Buck converter and the waveforms when b $V_{\text {out }}$ decreases, $\mathbf{c} V_{\text {out }}$ increases, $\mathbf{d} f_{\text {ref }}$ decreases and $\mathbf{e} f_{\text {ref }}$ increases

Fig. 10 Schematic of the proposed current-starved VCDL

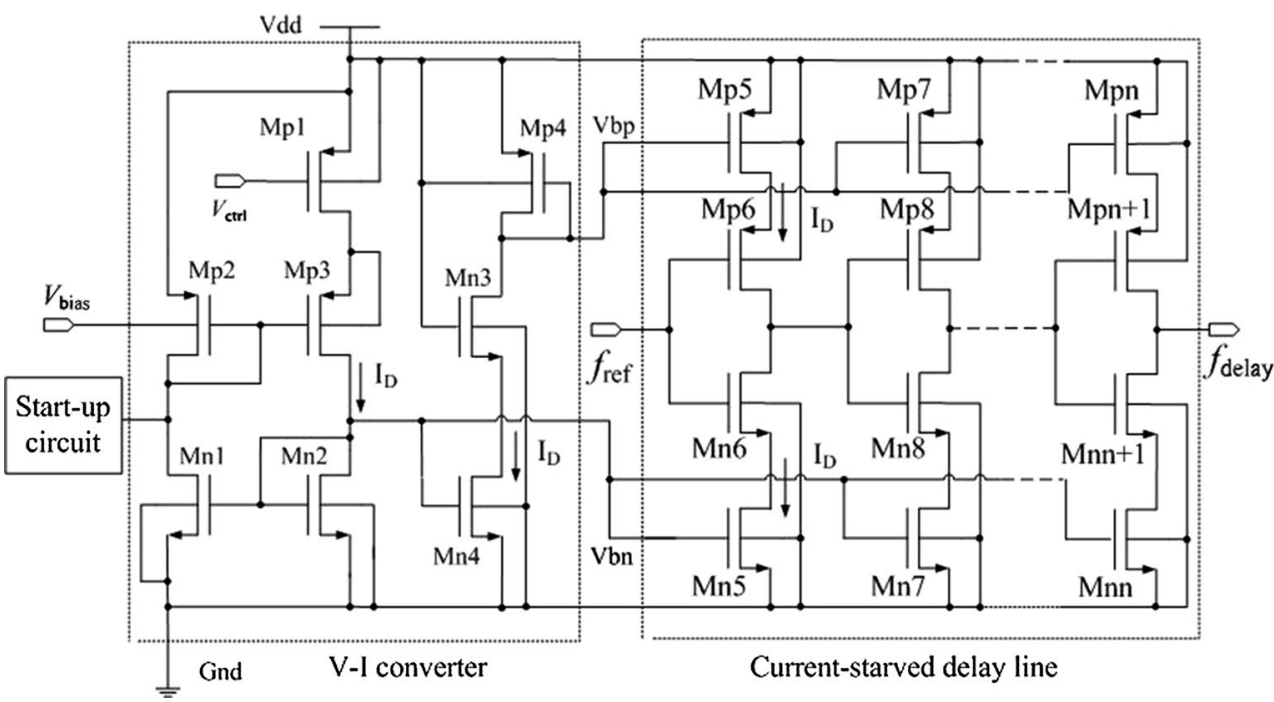

$t_{\text {delay_inv }}=\frac{C_{t o t} \times V_{d d}}{I_{D}}$

$$
\left\{\begin{array}{l}
\left(V_{G S}\right)_{M p 2}=\left(V_{G S}\right)_{M p 3}+\left(V_{D S}\right)_{M p 1} \\
\left(V_{T H}\right)_{M p 2}=V_{T H p 0}+\gamma\left(\sqrt{\left|2 \phi_{F}+V_{d d}-V_{\text {bias }}\right|}-\sqrt{\left|2 \phi_{F}\right|}\right) \\
\left(V_{D S}\right)_{M p 1} \approx-\frac{\left(I_{\text {drain }}\right)_{M p 1}}{(k)_{M p 1}\left[V_{c t r l}-V_{d d}-\left(V_{T H}\right)_{M p 1}\right]}
\end{array}\right.
$$

VCDL and $I_{\mathrm{D}}$ is the bias current of the inverter.

A V-I converter is designed to achieve a linear variation of $t_{\text {delay_inv. }}$ The structure of $\mathrm{V}-\mathrm{I}$ converter is shown in Fig. 10. Mp1 is controlled by $V_{\text {ctrl }}$. The symmetrical bias voltages $V_{\mathrm{bp}}$ and $V_{\mathrm{bn}}$ provide $\mathrm{DC}$ operating conditions of the transistors. They also determine the charging or discharging current $I_{\mathrm{D}}$ of $C_{\text {tot }}$ Mn1, Mn2 and Mn4 have the same dimensions, while $\mathrm{Mp} 2$ and Mp3 have the same dimensions. Mp1 operates in the linear-region. A bias voltage of $V_{\text {bias }}$, which is a little higher than $V_{\mathrm{dd}}$, is added to the bulk of Mp2 to lower the threshold voltage of $\mathrm{Mp} 2$. Following equations can be obtained: where $V_{\mathrm{GS}}$ is the gate voltage, $V_{\mathrm{DS}}$ is the voltage between drain and source, $V_{\mathrm{TH}}$ is the threshold voltage and $\phi_{F}$ is the Fermi potential. That is,

$$
\begin{aligned}
& -\sqrt{\frac{2\left|\left(I_{d r a i n}\right)_{M p 2}\right|}{(k)_{M p 2}}}+\left(V_{T H}\right)_{M p 2}=-\sqrt{\frac{2\left|\left(I_{\text {drain }}\right)_{M p 3}\right|}{(k)_{M p 3}}} \\
& +\left(V_{T H}\right)_{M p 3}-\frac{\left(I_{d r a i n}\right)_{M p 1}}{(k)_{M p 1}\left[V_{c t r l}-V_{d d}-\left(V_{T H}\right)_{M p 1}\right]}
\end{aligned}
$$


where $I_{\text {drain }}$ is the drain current of the MOSFET and $k$ is the transconductance coefficient. Considering that,

$$
\begin{aligned}
& \left(I_{\text {drain }}\right)_{M p 1}=\left(I_{\text {drain }}\right)_{M p 2}=\left(I_{\text {drain }}\right)_{M p 3}=-I_{D} \\
& \left(V_{T H}\right)_{M p 2}=\left(V_{T H}\right)_{M p 3}=V_{T H p 0} \\
& (k)_{M p 1}=(k)_{M p 2}=(k)_{M p 3}
\end{aligned}
$$

From equations from (6) to (9), we can obtain

$I_{D}=K \times\left(V_{c t r l}-V_{d d}-V_{T H p 0}\right)$

where

$K=\gamma \times\left(\sqrt{\left|2 \phi_{F}+V_{d d}-V_{\text {bias }}\right|}-\sqrt{\left|2 \phi_{F}\right|}\right) \times(k)_{M p 1}$.

$V_{T H p O}$ and $K$ are both process-related constants. $\gamma$ is the substrate bias coefficient, $\gamma<0$.

Assuming there are $N$ stage current-starved inverters in the VCDL, the total delay $t_{\text {delay }}$ of the VCDL is obtained by combining Eqs. (4) and (10).

$$
t_{\text {delay }}=\frac{N \times C_{t o t} \times V_{d d}}{K \times\left(V_{c t r l}-V_{d d}-V_{T H p 0}\right)}
$$

Therefore, combining Eqs. (3) and (11), the linear relationship between $V_{\text {ctrl }}$ and $f_{\text {ref }}$ is obtained as follows:

$f_{\text {ref }}=\frac{K \times\left(V_{\text {ctrl }}-V_{d d}-V_{T H p 0}\right)}{2 N \times C_{t o t} \times V_{d d}}$

The current-starved VCDL can work at an ultra low voltage, even the voltage a little higher than $0 \mathrm{~V}$ is acceptable, which makes it possible for the converter to regulate the ultra low output voltage of $0.5 \mathrm{~V}$.

\section{Circuit design and result discussion}

A DVS-enabled fast transient double Buck converter with a current-starved VCDL is designed in a $0.18 \mu \mathrm{m}$ CMOS process. The circuit configuration is shown in Fig. 11. The Clock Generator generates the periodic pulses for the Boost Circuit and the enable signals for the converter. A bias voltage $V_{\text {bias }}$ being a little higher than the supply voltage $V_{\text {in }}$ is generated by the Boost Circuit module to provide a $\mathrm{N}$-well bias of the VCDL. The Control Block generates the duty variation PFM control signals, which are sent to the Dead Time and Driving Block to drive the power switches. The converter operates in three modes: the high-voltage transient mode when $V_{\text {out }}$ is higher than $V_{\mathrm{o}}+\Delta V$, the lowvoltage transient mode when $V_{\text {out }}$ is lower than $V_{\mathrm{o}}-\Delta V$, and the steady-state mode when $V_{\text {out }}$ is between $V_{\mathrm{o}}-\Delta V$ and $V_{\mathrm{o}}+\Delta V$. The voltage and current references are generated by Bandgap and the Protection Circuit provides the protections of the chip.

The chip layout is shown in Fig. 12. The die area is $1.75 \mathrm{~mm} \times 1.33 \mathrm{~mm}$, including pads and ESD protections. The post-layout simulation results of the converter with

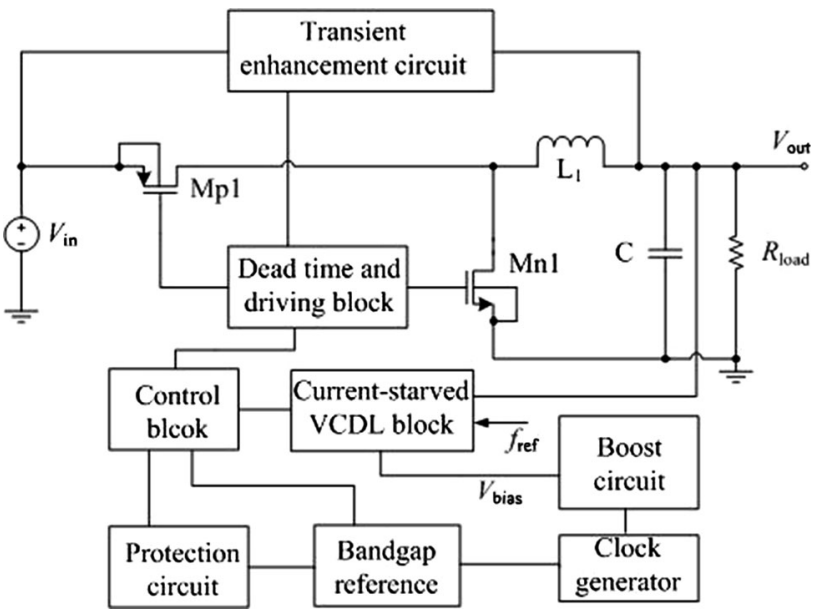

Fig. 11 Topology of the proposed DVS-enabled Buck converter

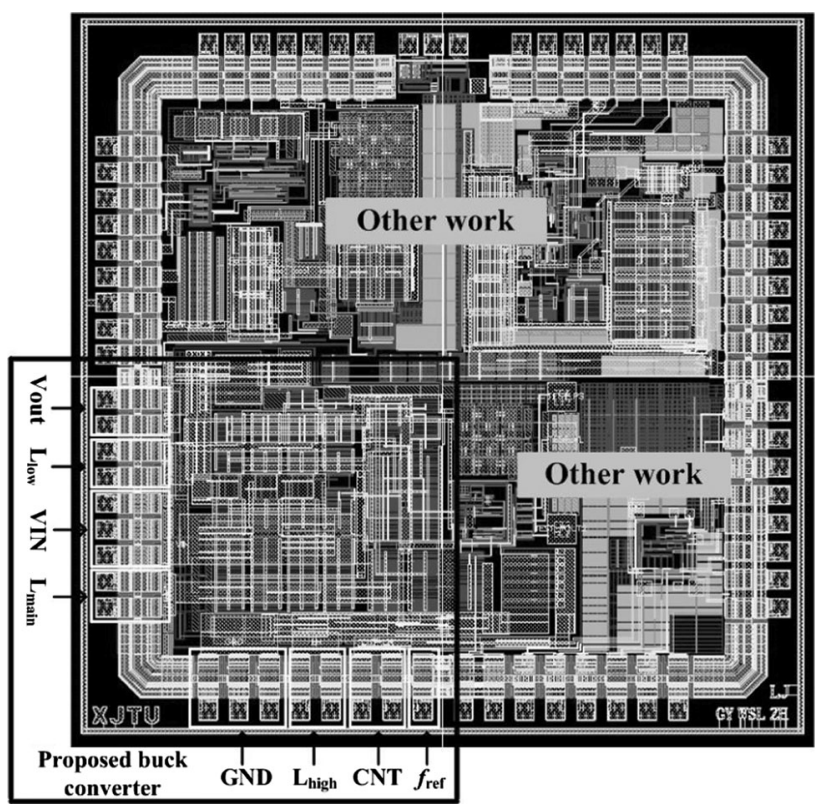

Fig. 12 Layout of the proposed converter

Process, Voltage and Temperature (PVT) variations are shown in Fig. 13. The same parameters as those of the hysteretic converter are used. Three process corners are simulated and the waveforms are divided into three groups, which depict the converter's transient characteristics. Figure 13(a-d) are the results under Typical NMOS and Typical PMOS (TNTP) corner, Fig. 13(e-h) are the results under Slow NMOS and Slow PMOS (SNSP) corner and Fig. 13(i-l) are the results under Fast NMOS and Fast PMOS (FNFP) corner. Take the TNTP corner as an example, Fig. 13(a) shows the waveforms of the converter with the output voltage step between $0.5 \mathrm{~V}$ and $1.8 \mathrm{~V}$. When the reference frequency $f_{\text {ref }}$ is $106 \mathrm{MHz}$, the output voltage of the converter $V_{\text {out }}$ is $0.5 \mathrm{~V}$. When the 


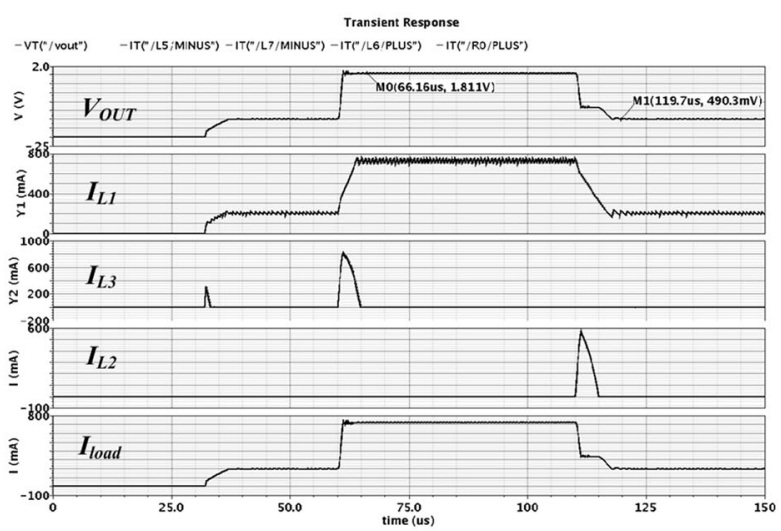

(a)

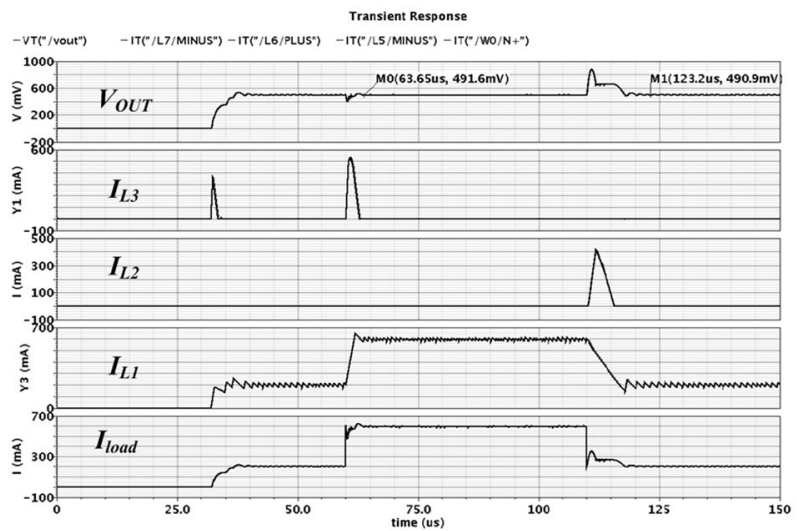

(c)

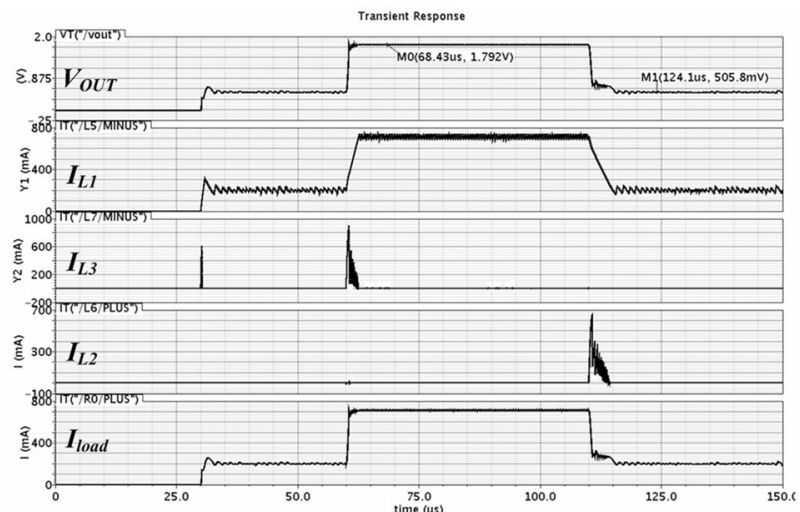

(e)

Fig. 13 Post-simulated waveforms with output-voltage/load-current step changes: a-d, $\mathbf{e}-\mathbf{h}$ and $\mathbf{i}-\mathbf{l}$ are the results under the TNTP corner, the SNSP corner and the FNFP corner, respectively. a, e, i are the results when output voltage is step-changed between 0.5 and $1.8 \mathrm{~V}$. b, $\mathbf{f}, \mathbf{j}$ are the results when output voltage is step-changed between 1.0

corresponding $f_{\text {ref }}$ changes to $57 \mathrm{MHz}, V_{\text {out }}$ is $1.8 \mathrm{~V}$. The voltage up-tracking speed of $4.74 \mu \mathrm{s} / \mathrm{V}$ and the downtracking speed of $7.46 \mu \mathrm{s} / \mathrm{V}$ are obtained. Figure 13(b) shows the results when the output-voltage

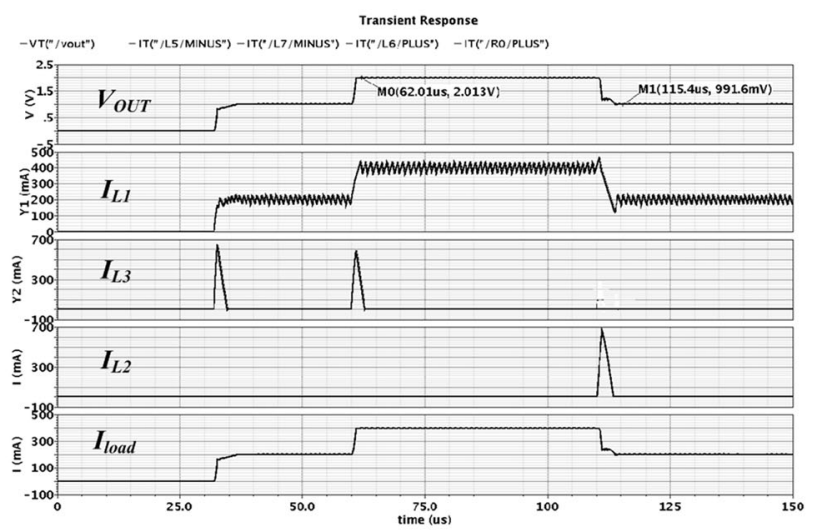

(b)

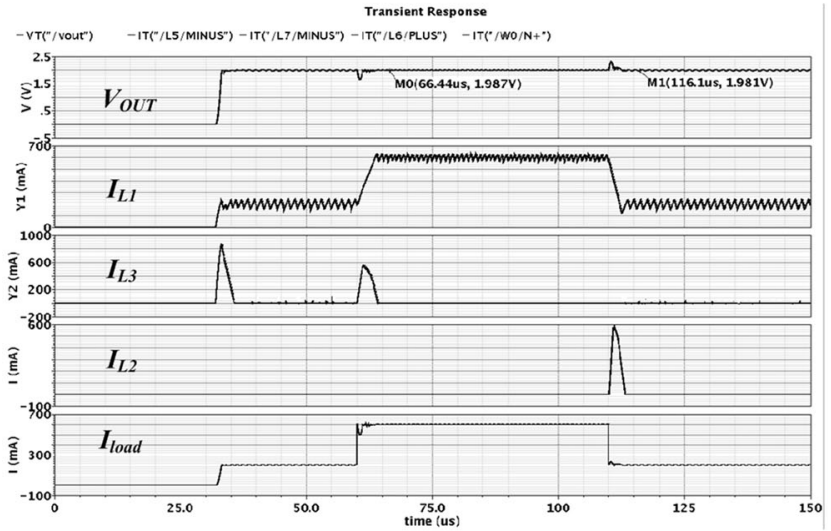

(d)

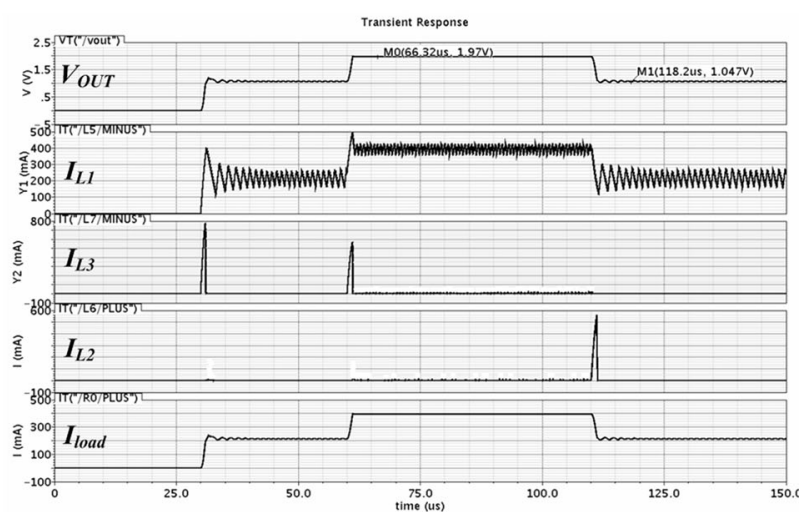

(f)

and $2.0 \mathrm{~V}$. c, g, $\mathbf{k}$ are the results when $V_{\text {out }}=0.5 \mathrm{~V}$ and output current is step-changed between 200 and $600 \mathrm{~mA}$. d, h, l $\mathbf{l}$ are the results when $V_{\text {out }}=2.0 \mathrm{~V}$ and output current is step-changed between 200 and $600 \mathrm{~mA}$

changes between $1.0 \mathrm{~V}$ and $2.0 \mathrm{~V}$. When $f_{\text {ref }}$ is $92 \mathrm{MHz}$, $V_{\text {out }}$ is $1.0 \mathrm{~V}$, while when $f_{\text {ref }}$ is $48 \mathrm{MHz}, V_{\text {out }}$ is $2.0 \mathrm{~V}$. The voltage up-tracking speed is $2.0 \mu \mathrm{s} / \mathrm{V}$ and the downtracking speed is $5.4 \mu \mathrm{s} / \mathrm{V}$. Figure $13(\mathrm{c}, \mathrm{d})$ show the 


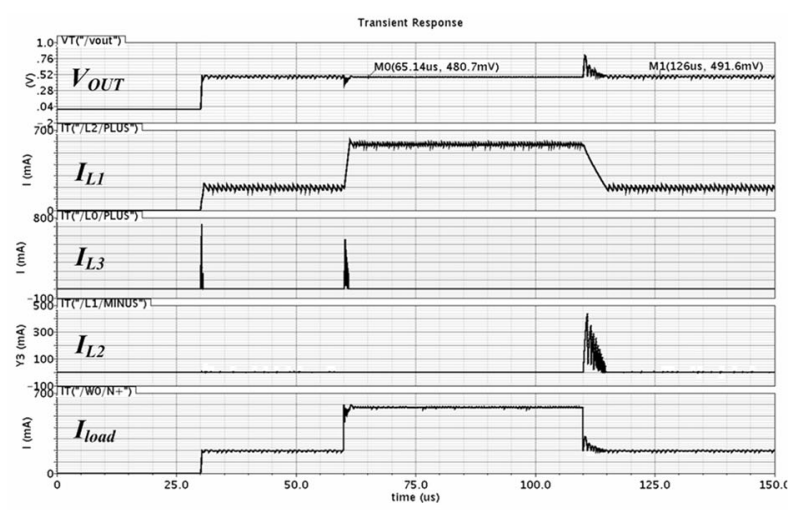

(g)

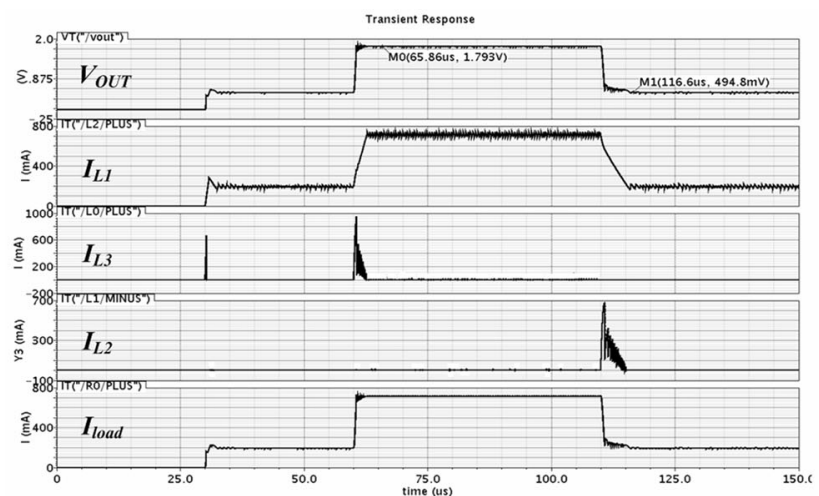

(i)

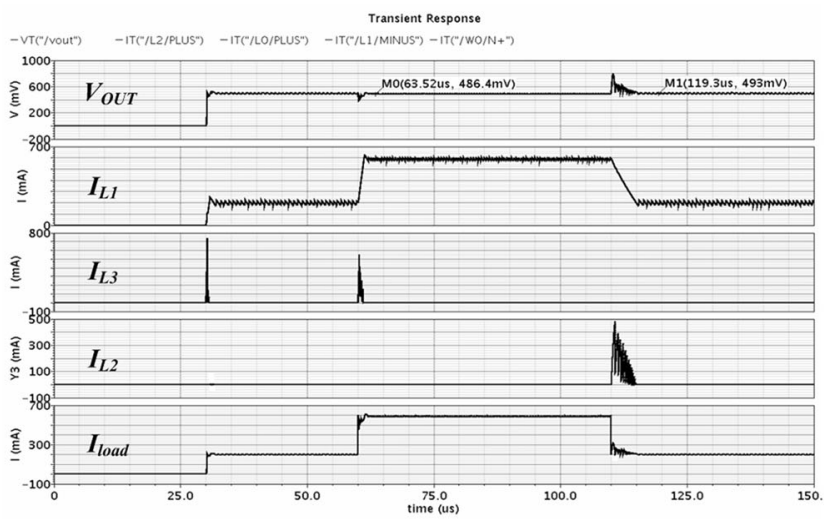

(k)

Fig. 13 continued

waveforms when the load-current of the converter changes between $200 \mathrm{~mA}$ and $600 \mathrm{~mA}$. When the output voltage is $0.5 \mathrm{~V}$, the load up-tracking speed of $9.13 \mu \mathrm{s} / \mathrm{A}$ and the down-tracking speed of $33.0 \mu \mathrm{s} / \mathrm{A}$ are obtained. When the output voltage is $2.0 \mathrm{~V}$, the up-tracking speed is $16.1 \mu \mathrm{s} / \mathrm{A}$ and the down-tracking speed is $15.25 \mu \mathrm{s} / \mathrm{A}$. Similarly, the voltage tracking speed and the load tracking speed under SNSP corner and FNFP corner can be obtained,

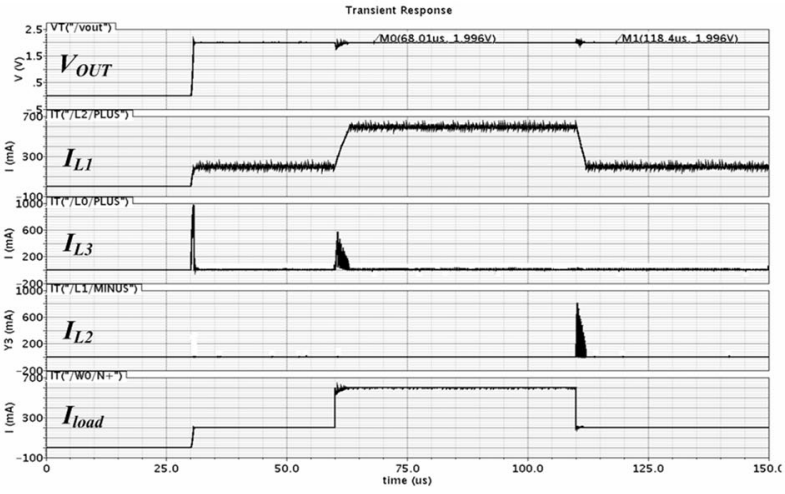

(h)

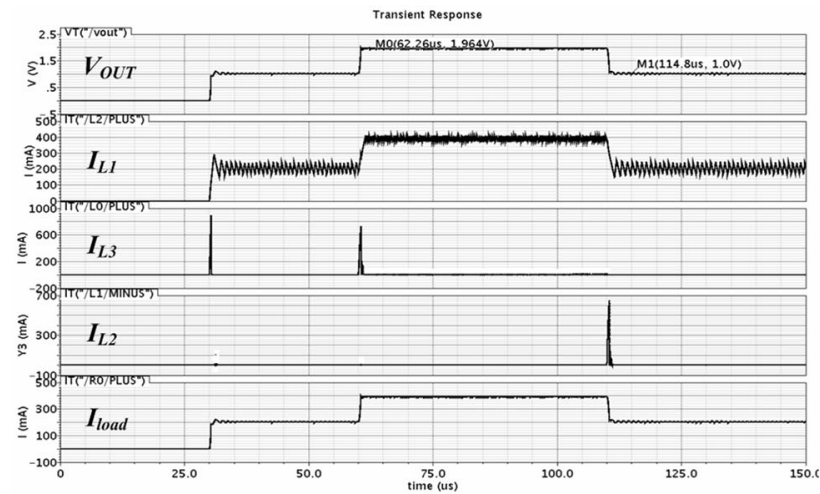

(j)

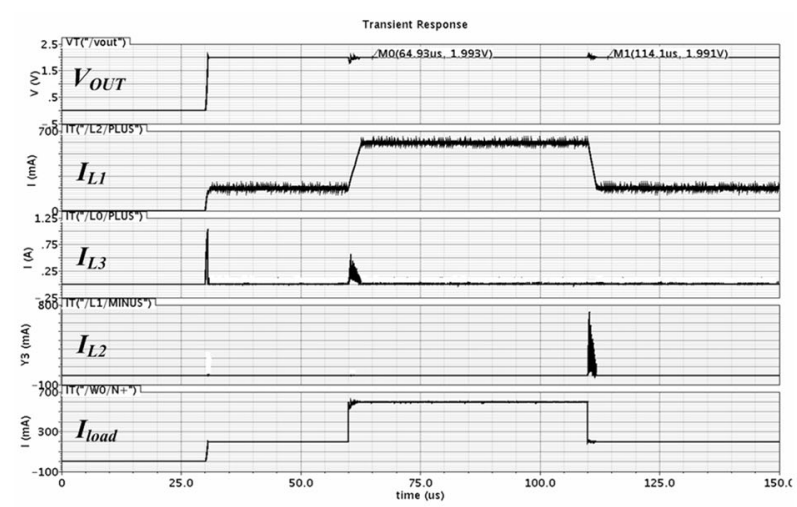

(l)

respectively, which are summarized in Table 2. This converter exhibits a slower transient response under the conditions of high junction temperature with SNSP corner than it does under the conditions of low junction temperature with FNFP corner. However, it is still a robust design against PVT variations.

Table 3 summarizes the features of the proposed converter. The output-voltage and the load-current tracking 
Table 2 Transient response of the proposed converter with PVT variations

\begin{tabular}{|c|c|c|c|}
\hline Parameters & Values & Values & Values \\
\hline Process corner & FNFP & TNTP & SNSP \\
\hline Input voltage & $3.6 \mathrm{~V}$ & $3.3 \mathrm{~V}$ & $3.0 \mathrm{~V}$ \\
\hline Temperature & $-40^{\circ} \mathrm{C}$ & $25^{\circ} \mathrm{C}$ & $125^{\circ} \mathrm{C}$ \\
\hline $\begin{array}{l}\text { Reference } \\
\text { frequency for } \\
0.5 \mathrm{~V} \text { output }\end{array}$ & $117 \mathrm{MHz}$ & $106 \mathrm{MHz}$ & $97 \mathrm{MHz}$ \\
\hline $\begin{array}{l}\text { Reference } \\
\text { frequency for } \\
2.0 \mathrm{~V} \text { output }\end{array}$ & $53 \mathrm{MHz}$ & $48 \mathrm{MHz}$ & $43 \mathrm{MHz}$ \\
\hline $\begin{array}{l}\text { Up-tracking } \\
\text { speed of the } \\
\text { output voltage }\end{array}$ & $\begin{array}{l}4.5 \mu \mathrm{s} / \mathrm{V} @ \\
\text { (from } 0.5 \text { to } \\
1.8 \mathrm{~V} \text { ) }\end{array}$ & $\begin{array}{l}4.7 \mu \mathrm{s} / \mathrm{V} @ \\
\text { (from } 0.5 \text { to } \\
1.8 \mathrm{~V} \text { ) }\end{array}$ & $\begin{array}{l}6.5 \mu \mathrm{s} / \mathrm{V} @ \\
\text { (from } 0.5 \text { to } \\
1.8 \mathrm{~V} \text { ) }\end{array}$ \\
\hline $\begin{array}{l}\text { Down-tracking } \\
\text { speed of the } \\
\text { output voltage }\end{array}$ & $\begin{array}{l}5.1 \mu \mathrm{s} / \mathrm{V} @ \\
\text { (from } 1.8 \text { to } \\
0.5 \mathrm{~V} \text { ) }\end{array}$ & $\begin{array}{l}7.5 \mu \mathrm{s} / \mathrm{V} @ \\
\text { (from } 1.8 \text { to } \\
0.5 \mathrm{~V} \text { ) }\end{array}$ & $\begin{array}{l}10.8 \mu \mathrm{s} / \mathrm{V} @ \\
\text { (from } 1.8 \text { to } \\
0.5 \mathrm{~V} \text { ) }\end{array}$ \\
\hline $\begin{array}{l}\text { Load up-tracking } \\
\text { speed }\end{array}$ & $\begin{array}{l}12.3 \mu \mathrm{s} / \mathrm{A} @ \\
\text { (from } 200 \text { to } \\
600 \mathrm{~mA} \text { ) }\end{array}$ & $\begin{array}{l}16.1 \mu \mathrm{s} / \mathrm{A} @ \\
\text { (from } 200 \text { to } \\
600 \mathrm{~mA} \text { ) }\end{array}$ & $\begin{array}{l}20.0 \mu \mathrm{s} / \mathrm{A} @ \\
\quad(\text { from } 200 \text { to } \\
600 \mathrm{~mA})\end{array}$ \\
\hline $\begin{array}{l}\text { Load down- } \\
\text { tracking speed }\end{array}$ & $\begin{array}{l}23.3 \mu \mathrm{s} / \mathrm{A} @ \\
\text { (from } 600 \text { to } \\
200 \mathrm{~mA} \text { ) }\end{array}$ & $\begin{array}{l}33.0 \mu \mathrm{s} / \mathrm{A} @ \\
\text { (from } 600 \text { to } \\
200 \mathrm{~mA} \text { ) }\end{array}$ & $\begin{array}{l}40.0 \mu \mathrm{s} / \mathrm{A} @ \\
\text { (from } 600 \text { to } \\
200 \mathrm{~mA} \text { ) }\end{array}$ \\
\hline
\end{tabular}

Table 3 Key features of the proposed converter

\begin{tabular}{|c|c|c|c|}
\hline Parameters & Values & Parameters & Values \\
\hline $\begin{array}{l}\text { Input } \\
\text { voltage }\end{array}$ & $3.0-3.6 \mathrm{~V}$ & $\begin{array}{l}\text { Load } \\
\text { current }\end{array}$ & $200-600 \mathrm{~mA}$ \\
\hline $\begin{array}{l}\text { Output } \\
\text { voltage }\end{array}$ & $0.5-2.0 \mathrm{~V}$ & $\begin{array}{l}\text { Switching } \\
\text { frequency }\end{array}$ & $0.74-1.71 \mathrm{MHz}$ \\
\hline $\begin{array}{l}\text { Linear } \\
\text { regulation }\end{array}$ & $\begin{array}{l}2.0 \% / \mathrm{V} @ \\
\quad\left(V_{\text {out }}=0.5 \mathrm{~V}\right)\end{array}$ & $\begin{array}{l}\text { Load } \\
\text { regulation }\end{array}$ & $\begin{array}{l}2.5 \% / \mathrm{A} @ \\
\quad\left(V_{\text {out }}=1.0 \mathrm{~V}\right)\end{array}$ \\
\hline $\begin{array}{l}\text { Output } \\
\text { voltage } \\
\text { tracking } \\
\text { speed }\end{array}$ & $\begin{array}{l}7.5 \mu \mathrm{s} / \mathrm{V} @ \\
\left(V_{\text {out }} \text { changes }\right. \\
\text { from } 1.8 \text { to } \\
0.5 \mathrm{~V})\end{array}$ & $\begin{array}{l}\text { Load } \\
\text { current } \\
\text { tracking } \\
\text { speed }\end{array}$ & $\begin{array}{l}33.0 \mu \mathrm{s} / \mathrm{A} @ \\
\left(\mathrm{~V}_{\text {out }}=0.5 \mathrm{~V}, I_{\text {load }}\right. \\
\text { changes from } 600 \\
\text { to } 200 \mathrm{~mA})\end{array}$ \\
\hline
\end{tabular}

speeds are compared with those of the previous works in Tables 4 and 5, respectively. This work shows the lowest minimal output voltage and thus a wider output-voltage range. Moreover, it has a faster output-voltage tracking speed comparing with the other DVS-enabled converters. Besides this, our work shows a superior load tracking capability.

\section{Conclusion}

A fast transient DVS-enabled Buck converter has been designed in this paper. The transient features of the
Table 4 Comparisons of the output-voltage tracking speed

\begin{tabular}{llll}
\hline Converter & This work $^{\mathrm{a}}$ & Work in [15] $^{\mathrm{b}}$ & Work in [16] $^{\mathrm{c}}$ \\
\hline Type & Buck & Buck & Boost \\
DVS & Enable & Enable & Enable \\
Input/output & $3.0-3.6 /$ & $2.7-3.3 /$ & $1.5 / 0.9-2.2 \mathrm{~V}$ \\
$\quad$ voltage range & $0.5-2.0 \mathrm{~V}$ & $0.8-1.6 \mathrm{~V}$ & \\
Up-tracking speed & $4.7 \mu \mathrm{s} / \mathrm{V} @$ & $12.5 \mu \mathrm{s} / \mathrm{V} @$ & $93.3 \mu \mathrm{s} / \mathrm{V} @$ \\
of the output & (from 0.5 to & (from 0.8 to & (from 1.2 to \\
voltage & $1.8 \mathrm{~V}$ ) & $1.2 \mathrm{~V})$ & $1.8 \mathrm{~V})$ \\
Down-tracking & $7.5 \mu \mathrm{s} / \mathrm{V} @$ & $22.5 \mu \mathrm{s} / \mathrm{V} @$ & $26.7 \mu \mathrm{s} / \mathrm{V} @$ \\
speed of the & (from 1.8 to & (from 1.2 to & (from 1.8 to \\
output voltage & $0.5 \mathrm{~V})$ & $0.8 \mathrm{~V})$ & $1.2 \mathrm{~V})$
\end{tabular}

a The results in this work are based on simulated data

b The results in [15] are based on simulated data

c The results in [16] are based on experimental data

Table 5 Comparisons of the load-current tracking speed

\begin{tabular}{|c|c|c|c|}
\hline Converter & This work $^{\mathrm{a}}$ & Work in $[17]^{b}$ & Work in $[18]^{c}$ \\
\hline Type & Buck & Buck & Buck \\
\hline $\begin{array}{l}\text { DVS } \\
\text { technique }\end{array}$ & Enable & Disable & Disable \\
\hline $\begin{array}{l}\text { Input/output } \\
\text { voltage }\end{array}$ & $\begin{array}{l}3.0-3.6 / \\
0.5-2.0 \mathrm{~V}\end{array}$ & $3.0-5.0 / 2.0 \mathrm{~V}$ & $3.3 / 2.0 \mathrm{~V}$ \\
\hline $\begin{array}{l}\text { Load up- } \\
\text { tracking } \\
\text { speed }\end{array}$ & $\begin{array}{l}16.1 \mu \mathrm{s} / \mathrm{A} @ \\
\text { (from } 200 \text { to } \\
600 \mathrm{~mA} \text { ) }\end{array}$ & $\begin{array}{l}37.5 \mu \mathrm{s} / \mathrm{A} @ \\
\text { (from } 100 \text { to } \\
500 \mathrm{~mA} \text { ) }\end{array}$ & $\begin{array}{l}66.7 \mu \mathrm{s} / \mathrm{A} @ \\
\text { (from } 100 \text { to } \\
400 \mathrm{~mA})\end{array}$ \\
\hline $\begin{array}{l}\text { Load down- } \\
\text { tracking } \\
\text { speed }\end{array}$ & $\begin{array}{l}33.0 \mu \mathrm{s} / \mathrm{A} @ \\
\text { (from } 600 \text { to } \\
200 \mathrm{~mA} \text { ) }\end{array}$ & $\begin{array}{l}20 \mu \mathrm{s} / \mathrm{A} @ \\
\text { (from } 500 \text { to } \\
100 \mathrm{~mA} \text { ) }\end{array}$ & $\begin{array}{l}83.3 \mu \mathrm{s} / \mathrm{A} @ \\
\text { (from } 400 \text { to } \\
100 \mathrm{~mA} \text { ) }\end{array}$ \\
\hline
\end{tabular}

a The results in this work are based on simulated data

b The results in [17] are based on simulated data

c The results in [18] are based on simulated data

voltage-mode PWM and hysteretic PFM converters are analyzed by using state trajectory. It can be concluded that PFM control shows better load and output voltage tracking capabilities than PWM control. Thus the hysteretic control is used and it also ensure the unconditional stability of the converter. Furthermore, a novel transient enhancement circuit is proposed based on the state trajectory analysis to effectively reduce the voltage oscillation and the overshooting during the mode transition. The transient recovery time of the Buck converter is improved. In hysteretic controller, the current-starved VCDL is designed to enable the output voltage of the converter reaching to a very low value of $0.5 \mathrm{~V}$, which is very suitable for the low supplyvoltage applications. The converter is designed in a $0.18 \mu \mathrm{m}$ CMOS technology. Post-layout simulation results show that the converter's output voltage can be dynamically regulated from 0.5 to $2.0 \mathrm{~V}$ with a load current range 
from 200 to $600 \mathrm{~mA}$. The tracking speed is less than $7.5 \mu \mathrm{s} / \mathrm{V}$ for the output-voltage step from 1.8 to $0.5 \mathrm{~V}$. For a load-current step from 0.6 to $0.2 \mathrm{~A}$, the tracking speed is within $33 \mu \mathrm{s} / \mathrm{A}$. The results show a better dynamic features compared with the other designs.

Acknowledgments We would like to thank the financial support from National Natural Science Foundation of China (60971049).

Open Access This article is distributed under the terms of the Creative Commons Attribution License which permits any use, distribution, and reproduction in any medium, provided the original author(s) and the source are credited.

\section{References}

1. Zhuo, J., Chakrabarti, C., Lee, K., Chang, N., \& Vrudhula, S. (2009). Maximizing the lifetime of embedded systems powered by fuel cell-battery hybrids. IEEE Transactions on Very Large Scale Integration Systems, 17(1), 22-32.

2. Vasic, M., Garcia, O., Oliver, J. A., Alou, P., \& Cobos, J.A. (2008). A DVS system based on the trade-off between energy savings and execution time. In 2008 COMPEL 11th Workshop on Control and modeling for power electronics (pp. 1-6).

3. Bang, S.-Y., Band, K., Yoon, S., \& Chung, E.-Y. (2009). Runtime adaptive workload estimation for dynamic voltage scaling. IEEE Transactions on Computer-Aided Design of Integrated Circuit and Systems, 28(9), 1334-1347.

4. Liu, P.-J., Chiu, H.-J., Lo, Y.-K., \& Chen, Y.-J. E. (2009). A fast transient recovery module for DC-DC converters. IEEE Transactions on Industrial Electronics, 56(7), 2522-2529.

5. Wang, J., Xu, J., \& Lan, Y. (2010). A fast transient recovery device for switching DC-DC converters. In 2010 International conference on communications, circuits and systems (ICCCAS) (pp. 569-571).

6. Ng, W. T., Wang, J., Ng, K., Prodic, A., Kawashima, T., Sasaki, M., et al. (2009). Digitally controlled integrated DC-DC converters with fast transient response. 2009 IEEE international symposium on Radio-frequency integration technology ( $\mathrm{pp}$. 335-338).

7. Luo, F., \& Ma, D. (2008). A low-ripple fast-response CMOS integrated switching buck converter with dual-mode pulse-train/ PWM control. In Power electronics specialists conference (pp. 3432-3436).

8. Lin, H.-C., Fung, B.-C., \& Chang, T.-Y. (2008). A current mode adaptive on-time control scheme for fast transient DC-DC converters. In International symposium on circuits and systems (pp. 2602-2605).

9. Burns, W. W., \& Wilson, T. G. (1976). State trajectories used to observe and control DC-to-DC converters. IEEE Transactions on Aerospace and Electronic Systems, 12(6), 706-717.

10. Ka-Sing Leung, K., \& Chung, H. S.-H. (2005). Dynamic hysteresis band control of the buck converter with fast transient response. IEEE Transactions on Circuits and Systems-II: Express Briefs, 52(7), 398-402.

11. Chung, H., \& Ioinovici, A. (1995). Large-signal stability of PWM switching regulators. In IEEE international symposium on circuits and systems, 1995. ISCAS'95 (pp. 1123-1126).
12. Zhang, C., Ma, D., \& Srivastava, A. (2004). Integrated adaptive DC/DC conversion with adaptive pulse-train technique for lowripple fast-response regulation. In International symposium on low power electronics and design (pp. 257-262).

13. Barrado, A., Lazaro, A., Vazquez, R., Salas, V., \& Olias, E. (2005). The fast response double buck DC-DC converter(FRDB): Operation and output filter influence. IEEE Transactions on Power Electronics, 20(6), 1261-1270.

14. Loveless, T. D., Massengill, L. W., Holman, W. T., \& Bhuva, B. L. (2007). Modeling and mitigating single-event transients in voltage-controlled oscillators. IEEE Transactions on Nuclear Science, 54(6), 2561-2567.

15. Kim, J., Chu, H., \& Kim, C. (2007). Current-mode DC-DC buck converter with reliable hysteretic-mode control and dual modulator for fast dynamic voltage scaling. In IEEE international Midwest symposiumon circuits and systems (pp. 941-944).

16. Zheng, C., \& Ma, D. (2010). A $10 \mathrm{MHz} 92.1 \%$-efficiency greenmode automatic reconfigurable switching converter with adaptively compensated single-bound hysteresis control. In 2010 IEEE international solid-state circuits conference digest of technical papers (pp. 257-262).

17. Lee, Y.-H., Wang, S.-J., Hsieh, C.-Y., \& Chen, K.-H. (2008). Current mode DC-DC buck converters with optimal fast transient control. In IEEE international symposium on circuits and systems (pp. 3045-3048).

18. Huang, H.-W., Ho, H.-H., Chang, C.-J., Chen, K.-H., \& Kuo, S.-Y. (2006). On-chip compensated error amplifier for fast transient DC-DC converters. In 2006 IEEE international conference on electro/information technology (pp. 103-108).

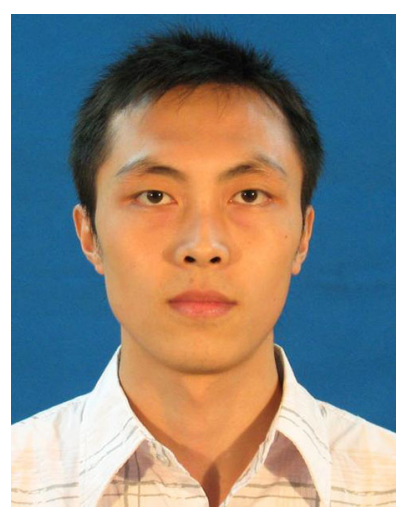

Jun Liu received the B.S. and M.S. degree in Electrical Engineering from Xi'an Jiaotong University, Shaanxi, China, in 2008 and 2011, respectively. Currently he is working in Verisilicon (Shanghai, China) Co., Ltd. His research and design interests are within the development of power management and mixed signal circuit and systems.

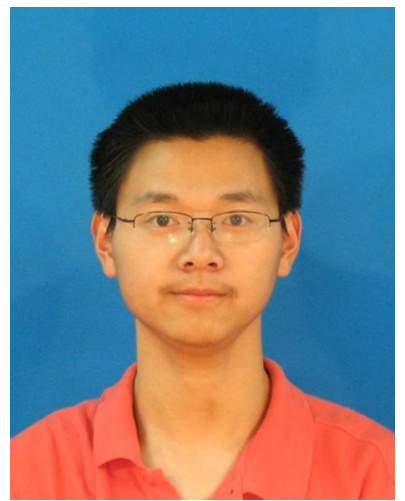

Leicheng Chen received the B.S. degree in microelectronics engineering from Xi'an Jiaotong University, Shaanxi, China, in 2010, He is currently working toward the M.S. degree in microelectronics engineering at Xi'an Jiaotong University. His current research interests include digital controlled DVS DC-DC converters and lowpower UWB transceivers. 


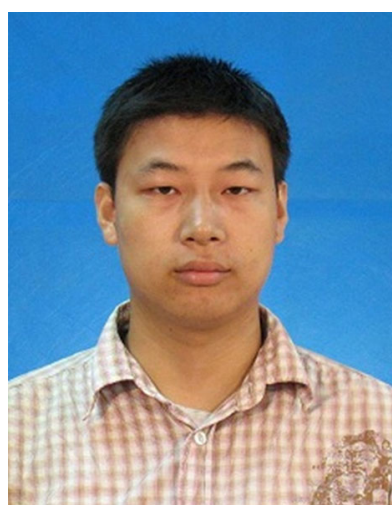

power electronics systems.
Shiquan Fan received the B.E. and M.E. degree from Xi'an Jiaotong University, Xi'an, China, in 2003 and 2009, respectively, both in electrical engineering. $\mathrm{He}$ is currently pursuing the Ph.D. degree in the School of Electronic and Information Engineering, Xi'an Jiaotong University. His research interests are in the area of mixed-signal circuits and system design, more specifically, integrated power management, and control methodology of
Li Geng received the B.S. degree in physics, M.S. and $\mathrm{Ph} . \mathrm{D}$. degree in electrical engineering in 1990, 1998 and 2001, respectively. She is currently the Professor at Department of Microeletronics in Xi'an Jiaotong University, China. Her research interests include power management, RF communication circuits, analog and medical electronics circuit design. 